\title{
Using the Analytic Hierarchical Process to Define Choices for Re-Using Rural Buildings: Application to an Abandoned Village in Sicily
}

\author{
Patrizia Russo, Lara Riguccio, Laura Carullo, Giovanna Tomaselli* \\ Department of Agri-Food and Environmental Systems Management, Catania University, Catania, Italia. \\ Email: "gitomas@unict.it \\ Received April $4^{\text {th }}, 2013$; revised June $7^{\text {th }}, 2013$; accepted June $29^{\text {th }}, 2013$ \\ Copyright (C) 2013 Patrizia Russo et al. This is an open access article distributed under the Creative Commons Attribution License, \\ which permits unrestricted use, distribution, and reproduction in any medium, provided the original work is properly cited.
}

\begin{abstract}
It has been recognised for some time that traditional rural buildings are a cultural and/or practical "resource" of the countryside. Inappropriate re-conversions can result in the waste of valuable economic resources and the loss of local heritage. Thus, before reconstruction is started the possible types of re-use should be accurately evaluated. This work develops a method, based on the Analytic Hierarchy Process, for identifying the best re-use of an abandoned village that was built in the first half of the last century. The method uses the guidelines of the countryside plan, and our work is a case study designed to verify whether or not it is suitable in this context. Five requisites for sustainable intervention were identified, as well as three alternative re-uses and five indicators. The hierarchical analysis was developed using two different approaches, one used three hierarchical levels, and the other used four. The results obtained for both approaches agree in suggesting the same model for re-use, but the four level approaches also supplied additional information which would be useful when planning projects with major social and cultural impact.
\end{abstract}

Keywords: Rural Resources; Architectural Resources; Cultural Resources

\section{Introduction}

It is well-known that old rural buildings are in many ways part of the resources of the countryside. In many cases they are of architectural importance, and testimonies of architectural styles which are linked not only to particular historical periods but also to particular places, and as such are real cultural resources [1]. They are also resources for many modern farms, which market and give added value to their products by emphasising the traditional roots of the farms, using images of traditional buildings. There are buildings which can be re-used for different purposes (social, cultural, accommodation, tourism, etc.) and thus they are important resources because they encourage the development of indirect activities linked to agriculture, and therefore, sustain the diversity of economic and social life in rural areas. They are resources which give added value to the rural landscape because they establish its particular character, as can be seen by the fact that the buildings of major importance are protected by regional and national edicts and laws [2].

${ }^{*}$ Corresponding author.
Unfortunately great economic investment is required when renovating ancient rural buildings. This is not only because of the number of buildings involved but also because of the level of disrepair into which most of them have fallen. Renovation is particularly difficult when a public authority is the owner of the property because, generally speaking, they lack the funds for renovation. Thus any renovation must be carried out with great care, with attention being concentrated on the correct choice of the new use of the building. Choosing inappropriate new uses may, indeed, result in further impoverishment of the cultural heritage, the waste of resources, and missing the opportunity to give value to and develop the area where the buildings are located.

The rural settlements established as "new foundations" in the period from 1922 to 1943 are also part of Italy's rural architectural heritage [3]. The rural hamlets of the "two fascist decades" were established after the First World War to meet the needs for social redevelopment and the modernisation of agriculture. The aim was to create favourable living conditions for farmworkers near to their workplaces by improving the quality of their 
housing.

Planned as a response to a specific social need and as part of an essentially functional mindset, the architecture of these villages is of a particular type. This was related to the need to confirm or redefine a recognisable local identity, while reinterpreting this in a "modern" way [4]. They were thus a meaningful sign of change in the rural landscape during that particular historical period.

Pennacchi [3] (2010) established that 147 such hamlets were built in Italy in that period. Of these, 36 were built in Sicily, and they are the expression of a technical culture which managed to maintain some independence and distance from the dominant ideology [5]. These villages were inhabited for some decades and were then slowly abandoned in the 1950s. Today they are the least inhabited and in a severe state of disrepair. This is particularly true for the ECLS villages (Ente di Colonizzazione del Latifondo Siciliano-Society for the Colonisation of the Sicilian Landed Estates) which were built in the early 1940s and immediately abandoned, firstly because of the events of the Second World War and then because the populations migrated to the cities $[6,7]$.

The remains of these settlements still characterise the internal landscape of Sicily. They are strongly evocative memorials of a historical epoch and important events, but they have partly or wholly lost the practical uses which could guarantee their continued occupation. Given their historical and cultural importance, ways of reconstructing them and finding new uses for them are needed which will guarantee to protect their historical value. Because restoration requires noteworthy levels of investment, it is important that various new uses for the villages should be considered, and the most sustainable ones chosen. A multicriteria approach is probably the best way of doing this.

Thus the objective of the research described in this study is to outline a method, based on a multi-criteria approach, for identifying the best re-use of abandoned rural hamlets, bearing in mind the particular situation of the specific area. The method was tested on a rural village built in Sicily in the 1920s, Borgo Giuliano. The method used in the case study could be applied in other similar contexts.

\section{Materials and Methods}

\subsection{Borgo Giuliano}

Borgo Giuliano lies between the Nebrodi mountains and Mt Etna in North East Sicily (Figure 1). It is situated in a rural area mainly dedicated to arable farming and pasture land. It is about $3 \mathrm{Km}$ south of the towns of San Teodoro and Cesarò. It has been owned by the municipality of San Teodoro since 1996.

The village was inaugurated on 18 December 1940.

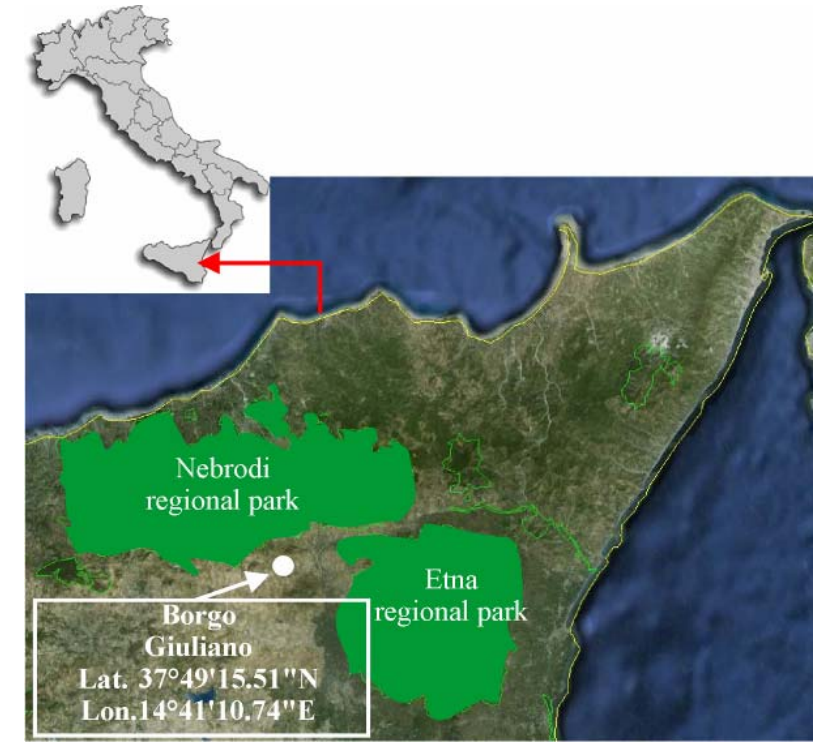

Figure 1. Plan of the area.

The name refers to a hero of the Fascist regime, Salvatore Giuliano. He was awarded the Gold medal for civil values and was killed in Africa.

The village is catalogued as part of the historical and cultural heritage in the Regional Countryside Plan, which also highlights the risks of abandoning the village and the need for a reconstruction aimed at conserving and giving value to its particular historical and architectural heritage.

\subsection{Hierarchical Analysis}

Here hierarchical analysis is used to compare, evaluate and tabulate the alternative re-uses of the abandoned rural villages.

The Analytic Hierarchy Process (AHR) was used [812]. This is based on constructing a square matrix with the elements that need to be hierarchically organised shown in both in linear and column form. Each element $x_{m n}$ and the results of the comparisons between the linear indicators $m$ and the columns $n$ are presented in relationship to the objectives which one wishes to achieve. These comparisons were carried out using Saaty's numerical and linguistic scale [8].

The objective was to identify the best hypotheses for reuse of the village choosing between alternatives which were aimed at social and cultural uses and suitable for direct and indirect public management (concessionary contracts for private companies).

The following alternatives were proposed:

$\mathrm{A}_{1}$-Development of a multi-functional centre;

$\mathrm{A}_{2}$-Active conservation of the ruins;

$\mathrm{A}_{3}$ - An on site virtual museum.

Alternative $A_{1}$ is based on developing a multi-func- 
tional centre which can serve the surrounding area. In synthesis, such as centre would provide the opportunity for carrying out cultural and experimental activities, offer support to farm workers and other artisans, and be used for recreational and restorative and therapeutic (hippotherapy) activities. In this case important reconstruction of the village would be necessary.

Alternative $A_{2}$ is based on the hypothesis of giving added value to the village by conserving the ruins and aiming only to make them physically safe and thus usable and accessible for cultural activities. The centre could be the hub of a network of sites, some of which already exist. These sites are already of environmental and cultural interest, including historical centres, contain examples of new purpose built rural architecture and the resources in local regional and national parks, as well as others which have yet to be established. An example of the latter is the slow connection of historical roads or the existing footpaths. The ruins are not only testimony to a historical period but are also homes to wild animals, and provide the soil and substrata for the spontaneous growth of wild vegetation. Thus in this case, apart from its cultural and tourism functions, the village also has a role to play as part of the ecological network $[13,14]$.

Alternative $\mathrm{A}_{3}$ consists of developing a web application which would allow a virtual reality to be constructed. Citizens could then use this to gain access to historical artistic and archaeological cultural information about the buildings by simply moving inside the virtual space and clicking on the objects [15].

This is a model for a virtual multimedia and interactive visit based on two principal modules. The first would allow the high-resolution three-dimensional visualisation of the village, with a reconstruction of its history ending with a visual representation of the details of the existing monuments. The second, by contrast, would be the creation of a database of all the valuable buildings based on a digital map of the village.

The first objective is to improve the communications of all the "cultural systems" of the population. This is so that citizens and tourists can better understand what they are going to look at and also to use new technology to give added value to the culture. This technology can enhance the spectacular features of certain historical places without ignoring their scientific and educational importance. In this case the idea is to reconstruct only those buildings which are in a better state of repair so that they can be used as multimedia centres for promoting tourism and the local culture.

Thus, given that the objective is to identify the form of sustainable reuse which will create new opportunities for rural development, the following indicators and criteria were chosen:
$\mathrm{I}_{1}$ - acceptable reconstruction costs for the buildings;

$\mathrm{I}_{2}$ - nearness to infrastructure;

$\mathrm{I}_{3}$ - nearness to historic centres;

$\mathrm{I}_{4}$-nearness to natural sites and other elements of the ecological network;

$\mathrm{I}_{5}$ - Nearness to business centres.

These indicators were defined as follows:

$\mathrm{I}_{1}$-Acceptable reconstruction costs for the buildings: There are always negative (costs) and positive (benefits) aspects whenever work is carried out to reach an objective. Comparing these is the general procedure for assessing whether such work is appropriate. The acceptability of the costs is here evaluated qualitatively, bearing in mind the costs of the total or partial reconstruction of the buildings and the value of their eventual reuse.

$\mathrm{I}_{2}$ - Nearness to infrastructure: the presence and the condition of the road infrastructure are factors which affect the development of the village. The presence of a good transport network is a positive factor in any reconstruction activity.

$\mathrm{I}_{3}$ - Nearness to historic centres: the historic centres are resources of the area which can be part of a historical and cultural network that will also link the rural villages. They are of marked importance for development of tourism in the area.

$\mathrm{I}_{4}$ - Nearness to natural sites and other elements of the ecological network and isolated valuable sites: the components of the natural and semi-natural countryside are the vegetation and the fauna and these are connected to it and are part of its dynamic process of change. The nature reserves are not only of ecological and cultural importance but also are important for tourism. The ruined buildings can form part of the ecological network and/or be part of cultural and nature tourism. This is also true for the architecture and defensive structures (castles, fortifications, towers etc.) built over the centuries, which are still recognisable or are in ruins. Irrespective of their state of disrepair, these territorial resources are in any case historically and environmentally important in that they have an irreplaceable role to play in making people aware of and remembering the historical and architectural origins of the area. They also have environmental importance because of their location, which is testimony to the relationship between particular prominent and dominant features of the landscape and control of the territory.

$\mathrm{I}_{5}$ - Nearness to business centres: this refers to farms which can offer services (accommodation, selling of local produce) and which require other services (local markets, support services, etc.).

The choice of the alternatives and the indicators is based on the analysis of certain papers which studied the same themes as the present work [16-21]. 


\section{Development of a Hierarchical Analysis}

Two methods were used for the hierarchical analysis. The first used three hierarchical levels (Figure 2) the second four (Figure 3). This is so that we could check whether or not the results were the same, as if they were this would reinforce the significance and reliability of the method. The first method was developed by constructing a first matrix which showed the weighting of each indicator for each alternative hypothesis. The weightings were the result of the qualitative judgements of the research group, based on their experience in the field and their knowledge of the literature. The judgements were measured on the matrix by the symbols,,,++++-- and -- (qualitative measurement units), where ++ represented the highest satisfaction value for the indicator $I_{n}$ with respect to the alternative $A_{m}$ and, vice versa, the symbol - represented the lack of satisfaction of the indicator $I_{n}$ with respect to the alternative $A_{m}$.

Normalisation was then carried out in order to make the data in the matrices homogeneous and useful for analysis. This gave the oral judgement ++ a value equal to 1 and the oral judgement - a value equal to 0 .

Pairwise comparison of the indicators was carried out for each alternative, and this provided the weightings which were attributed to the results of the first matrices. In his way the different hypotheses for reuse could be arranged hierarchically. In this case the Saaty scale (1980) was used for the weightings (1-Equal importance, 3Moderate importance of one over another; 5-Essential or strong importance; 7-Very strong importance; 9Extreme importance).

In the second procedure, while the objective was still the sustainability of the reconstruction of the village, hypotheses $A_{1}, A_{2}$ and $A_{3}$, were compared in terms of their economic advantages $(\mathrm{E})$, their cultural and tourism uses (T), their social use (S) and their suitability for developing an ecological network $(\mathrm{N})$. These requisites are essential if the intervention is to be sustainable [20]. In this way one can verify to what extent the hypotheses for eventual reuse satisfy these needs.

\section{Results and Discussion}

\subsection{Characteristics of the Village}

Borgo Giuliano is an emblematic example of the fate of rural villages in Sicily. It was built on soil subject to landslides and these have made the buildings unusable. Today it is in danger of disappearing completely.

The plan of the village is simple (Figure 4). The first buildings (the trattoria and the artisans' workshops) line the right hand side of the entry road. This road leads to a square whose sides are formed by other buildings (the church with a canonical annex and a sacristy, the city

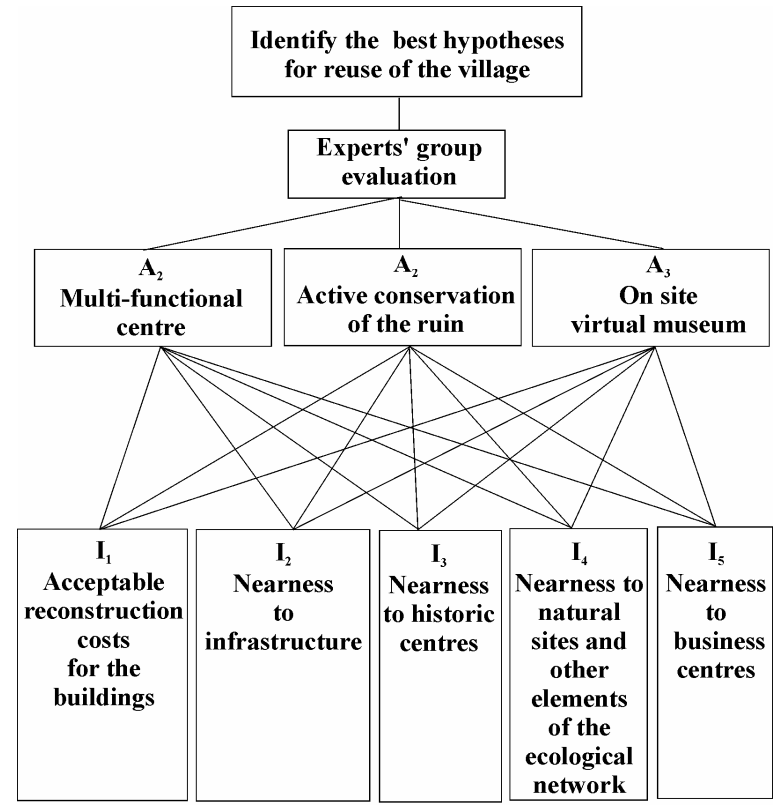

Figure 2. Structure of a three level hierarchical analysis.

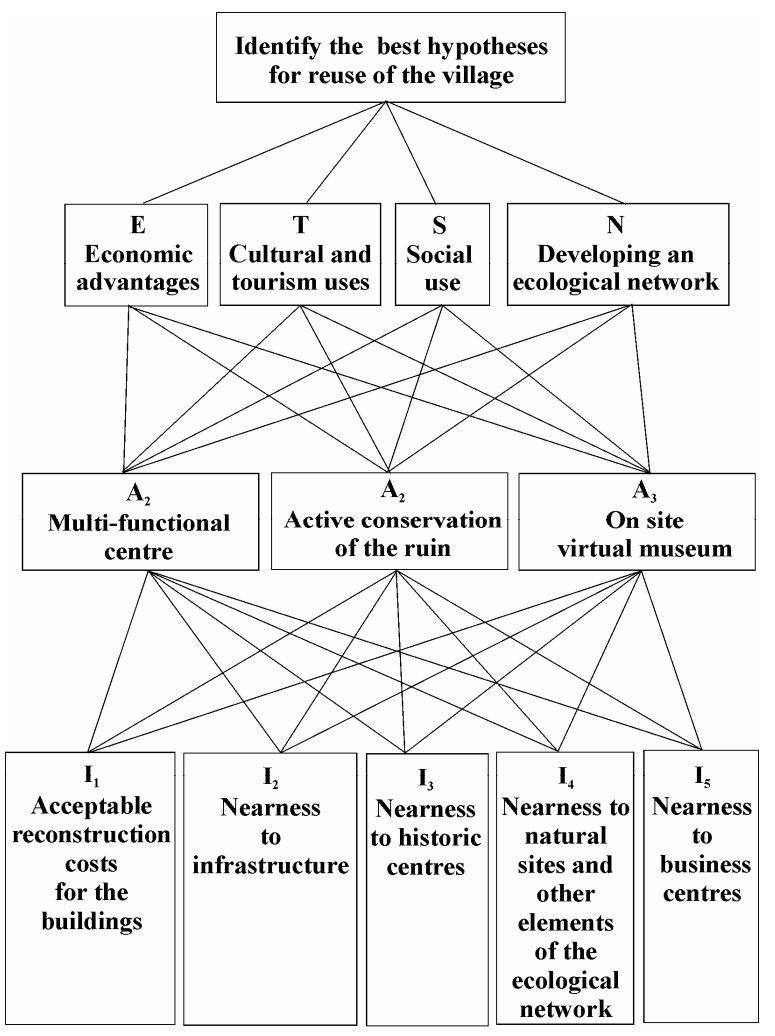

Figure 3. Structure of a four level hierarchical analysis.

hall, the offices of the ECLS organisation, the government offices, the school and the laundry). All these buildings were built with vertical brick walls and concrete floors. They were organised differently, depending on whether their role was formal or functional. The trattoria 


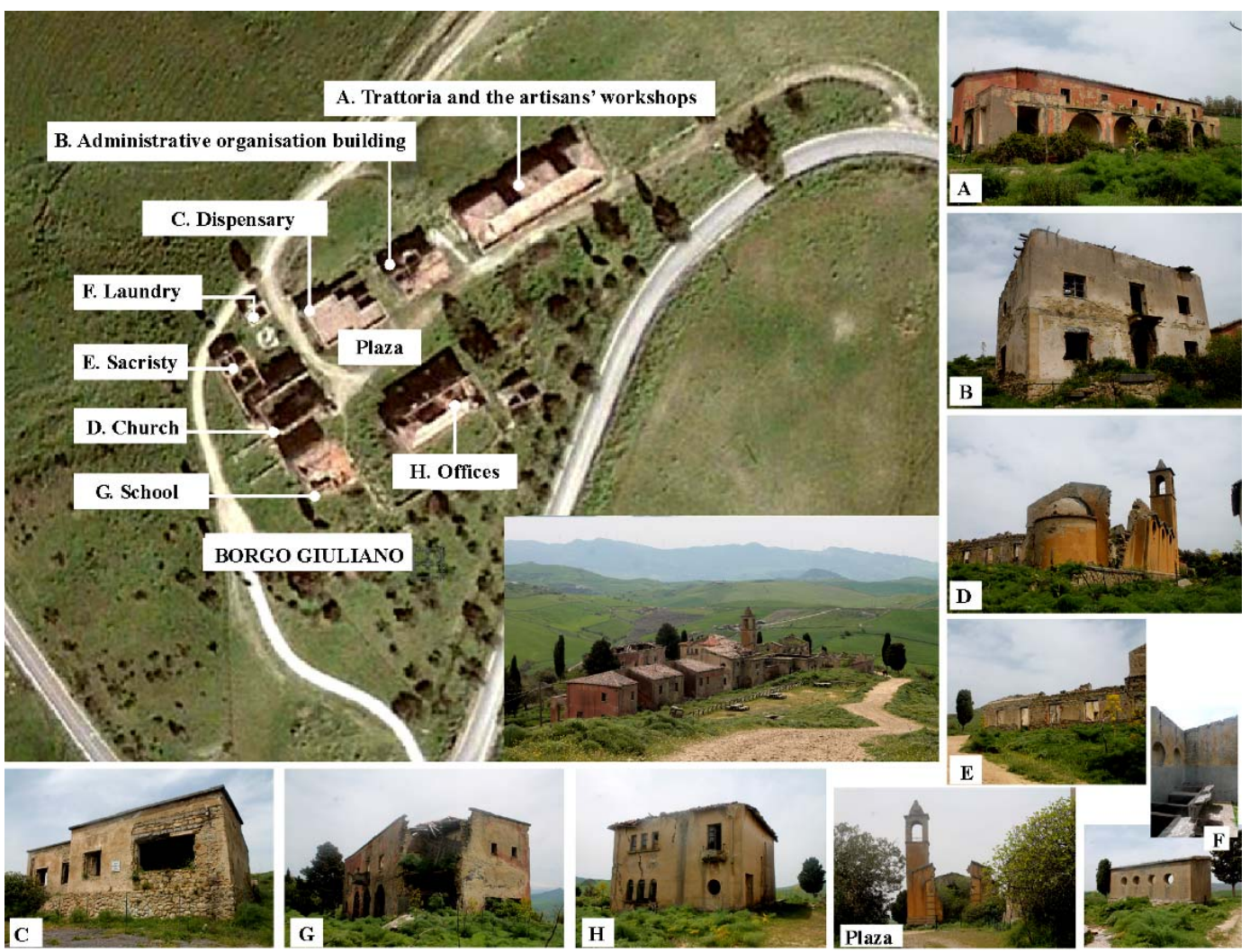

Figure 4. Plan of the village.

and the artisans' workshops (A) are in a two-storey building. It has a long arcade in uncut irregular stone and an iron parapet set in concrete.

The administrative organisation building (B) is also a two storey building. Distinctive elements are the brick windowsills and the small brick balconies. The dispensary (C) is a small single story slightly L shaped building. It is the only building in the village with a roof terrace. The church (D) has a single nave flanked by six small chapels, three on each side. The nave has a ridged roof while the chapels' roofs are dome shaped. The facade is plastered, with lava stone borders and a base in local stone. The bell tower is on the left of the church and its walls are topped with a reinforced concrete spire. The sacristy (E) and parochial and canonical offices are to the right of the church, and next to them is the laundry $(\mathrm{F})$. The school (G) is a two-storey square-shaped building with a triple lancet window on its facade.

Today the village is in ruins. The walls are tumbling down and irregular and disintegrating. Some of the walls have been undermined by the roots of the plants growing inside them. The loss of their plaster covering has exposed the walls to rain erosion. The remaining plaster is very weak because of atmospheric and plant erosion, with pieces of plaster detaching themselves from the walls [6].
A winding paved road connects the village to the medieval towns of Cesarò and San Teodoro. There is also a network of dirt paths around the village which connect it to a wooded area about one kilometre to the north as well as to the surrounding fields of cereal crops. Here there are many farms and certain structures of historical and cultural importance (rural houses, drinking troughs, store houses) which are under the supervision of the landscape plan. The village lies a few kilometres away from the border of the province of Catania and the regional parks of Nebrodi and Mount Etna (Figure 5) [22].

\subsection{Application of the Hierarchical Analysis}

\subsubsection{Application Using Three Hierarchical Levels}

Hierarchical analysis was used to reach the goal of identifying the best solution for reuse which was also compatible with public administration of the assets. In this case, three alternative levels were used $\left(A_{1}, A_{2}, A_{3}\right)$ and evaluation matrices were constructed (Table 1) which were made up of the five indicators $\left(\mathrm{I}_{1}, \mathrm{I}_{2}, \mathrm{I}_{3}, \mathrm{I}_{4}, \mathrm{I}_{5}\right)$ and he three alternatives $\left(A_{1}, A_{2}, A_{3}\right)$. The indicators (described above) represent the decisional variables involved in the problem.

The qualitative evaluations are registered in the matrices by the symbols,,,++++-- and -- (qualitative units of measurement). 
Table 1. Evaluation matrices: qualitative and normalised weightings.

\begin{tabular}{cccc}
\hline & $\mathbf{A}_{\mathbf{1}}$ & $\mathbf{A}_{\mathbf{2}}$ & $\mathbf{A}_{\mathbf{3}}$ \\
\hline $\mathbf{I}_{\mathbf{1}}$ & -- & ++ & + \\
$\mathbf{I}_{\mathbf{2}}$ & ++ & ++ & ++ \\
$\mathbf{I}_{\mathbf{3}}$ & - & + & + \\
$\mathbf{I}_{\mathbf{4}}$ & - & + & +- \\
$\mathbf{I}_{\mathbf{5}}$ & - & + & + \\
\hline & $\mathbf{A}_{\mathbf{1}}$ & $\mathbf{A}_{\mathbf{2}}$ & $\mathbf{A}_{\mathbf{3}}$ \\
\hline $\mathbf{I}_{\mathbf{1}}$ & 0.00 & 1.00 & 0.75 \\
$\mathbf{I}_{\mathbf{2}}$ & 1.00 & 1.00 & 1.00 \\
$\mathbf{I}_{\mathbf{3}}$ & 0.25 & 0.75 & 0.75 \\
$\mathbf{I}_{\mathbf{4}}$ & 0.25 & 0.75 & 0.50 \\
$\mathbf{I}_{\mathbf{5}}$ & 0.25 & 0.75 & 0.75 \\
\hline
\end{tabular}

--: $0 ;-: 0.25 ;+-: 0.50 ;+: 0.75 ;++: 1.00 ; \mathbf{A}_{1}$-Development of a multi-functional centre; $\mathbf{A}_{2}$-Active conservation of the ruins; $\mathbf{A}_{3}-\mathrm{An}$ on site virtual museum; $\mathbf{I}_{1}$-Acceptable reconstruction costs for the buildings; $\mathbf{I}_{2}-$ Nearness to infrastructure; $\mathbf{I}_{3}-$ Nearness to historic centres; $\mathbf{I}_{4}-$ Nearness to natural sites; $\mathbf{I}_{5}-$ Nearness to business centres.

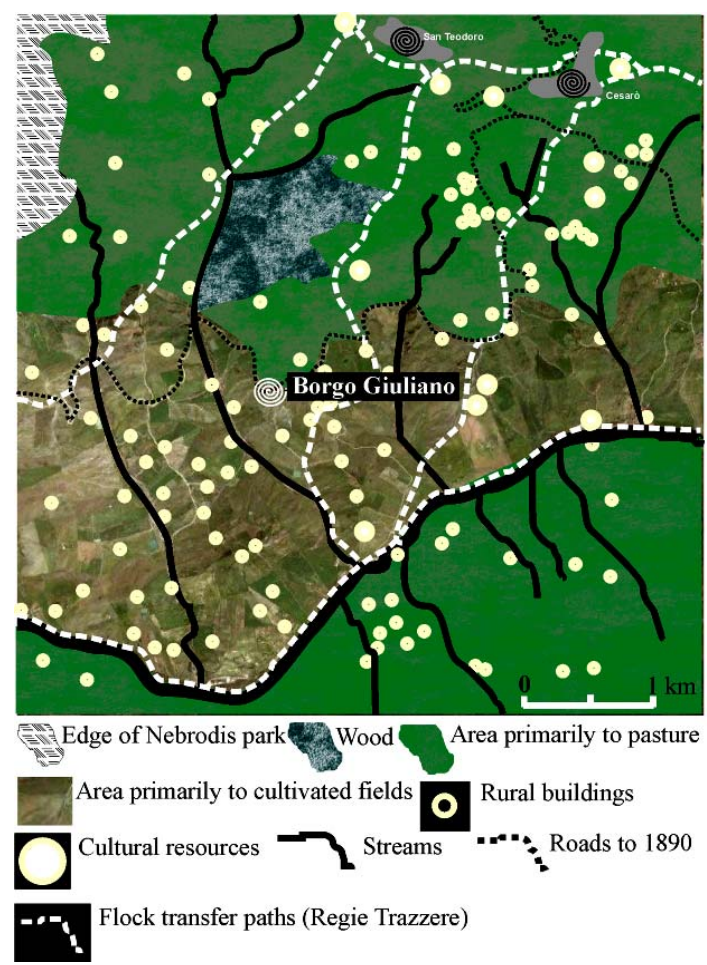

Figure 5. Main resources of the area.

The costs of reconstruction of buildings were greatest $\left(I_{1}\right)$ in alternative $A_{1}$, and thus this indicator was given a more negative value than the others. The costs of the other alternatives was, by contrast, progressively less, because in $\mathrm{A}_{3}$ the building work was partly renovation and partly consolidation of the ruins and in $\mathrm{A}_{2}$ consisted of making the ruins safe by means of structural consoli- dation.

The infrastructure $\left(\mathrm{I}_{2}\right)$ was judged positively for hypotheses $A_{2}$ and $A_{3}$, because of the types of use it would be put to (non-motorised traffic, nature, and cultural use), while it was negative for $A_{1}$ because the types of re-use, including commercial ones, required direct connections to the road and infrastructure network and being closer to urban centres.

Nearness to historic centres $\left(\mathrm{I}_{3}\right)$ positively influenced the uses connected to giving added value to tourism in the village $\left(A_{2}\right.$ e $\left.A_{3}\right)$ while it had little impact on reuse for social purposes $\left(\mathrm{A}_{1}\right)$.

The presence of nature sites or elements which would be suitable for being part of an ecological network near the village $\left(\mathrm{I}_{4}\right)$ (regional parks, woods to the North, water courses surrounded by spontaneous vegetation and ruined buildings) suggested that the indicators should be judged positively, in particular $A_{2}$. The natural resources had less value for the indicator which was aimed above all at giving added value to the architecture of the village $\left(A_{3}\right)$ and almost none for that for multi-functional reconversions $\left(\mathrm{A}_{1}\right)$.

Nearness to business centres $\left(\mathrm{I}_{5}\right)$ was evaluated as positive for all the hypotheses because it would provide support for culture and tourism and at the same time would justify the creation of commercial and support services inside the village.

The qualitative judgements were normalised and the sign ++ given a value of 1 and the sign -- one of 0 (Table 1), so that the data in the matrices was homogeneous and could be worked with.

Pairwise comparison matrices were constructed so that the relative order of importance of the three indicators could be established $\left(\mathrm{I}_{\mathrm{n}}\right)$ for each of the three reuse hypotheses $\left(A_{1}, A_{2}, A_{3}\right)$. These are shown in Table 2.

The qualitative judgements were inserted in the matrices using a-dimensional numerical values based on Saaty's numerical/linguistic scale [8].

The questions posed when composing the matrices were as follows:

- How much more important is the column indicator than the line indicator for hypothesis $A_{1}$, the creation of a multifunctional centre?

- How much more important is the column indicator than the line indicator for hypothesis $\mathrm{A}_{2}$, active conservation of the ruins?

- How much more important is the column indicator than the line indicator for hypothesis $\mathrm{A}_{3}$, an on-site virtual museum?

For hypothesis $A_{1}$, Indicator $I_{1}$, the acceptability of economic investment, was far more important than nearness to natural areas $\left(\mathrm{I}_{4}\right)$. Thus it depended of the irrelevance of the latter for the social functions and services of the village. 
Table 2. Pairwise comparison of the indicators for the three reuse hypotheses.

\begin{tabular}{|c|c|c|c|c|c|c|c|c|c|c|}
\hline \multicolumn{11}{|c|}{ Alternative $\mathbf{A}_{\mathbf{1}}$} \\
\hline & $\mathbf{I}_{\mathbf{1}}$ & $\mathbf{I}_{2}$ & $\mathbf{I}_{3}$ & $\mathbf{I}_{4}$ & $\mathbf{I}_{5}$ & GM & PV & $\mathbf{k}$ & CI & CR \\
\hline $\mathbf{I}_{1}$ & 1.00 & 1.00 & 2.00 & 5.00 & 2.00 & 1.82 & 0.32 & 1.03 & & \\
\hline $\mathbf{I}_{2}$ & 1.00 & 1.00 & 2.00 & 4.00 & 1.00 & 1.52 & 0.27 & 1.00 & & \\
\hline $\mathbf{I}_{3}$ & 0.50 & 0.50 & 1.00 & 3.00 & 2.00 & 1.08 & 0.19 & 1.11 & & \\
\hline $\mathbf{I}_{4}$ & 0.20 & 0.25 & 0.33 & 1.00 & 0.50 & 0.38 & 0.07 & 1.01 & & \\
\hline $\mathbf{I}_{5}$ & 0.50 & 1.00 & 0.50 & 2.00 & 1.00 & 0.87 & 0.15 & 1.00 & & \\
\hline Sum & 3.20 & 3.75 & 5.83 & 15.0 & 6.50 & 5.68 & 1.00 & 5.15 & 0.04 & 0.03 \\
\hline \multicolumn{11}{|c|}{ Alternative $\mathbf{A}_{2}$} \\
\hline & $\mathbf{I}_{1}$ & $\mathbf{I}_{2}$ & $\mathbf{I}_{3}$ & $\mathbf{I}_{4}$ & $\mathbf{I}_{5}$ & GM & PV & $\mathbf{k}$ & CI & CR \\
\hline $\mathbf{I}_{1}$ & 1.00 & 1.00 & 3.00 & 1.00 & 1.00 & 1.25 & 0.24 & 1.03 & & \\
\hline $\mathbf{I}_{2}$ & 1.00 & 1.00 & 5.00 & 1.00 & 0.50 & 1.20 & 0.23 & 1.19 & & \\
\hline $\mathbf{I}_{3}$ & 0.33 & 0.20 & 1.00 & 0.50 & 1.00 & 0.51 & 0.10 & 1.16 & & \\
\hline $\mathbf{I}_{4}$ & 1.00 & 1.00 & 2.00 & 1.00 & 1.00 & 1.15 & 0.22 & 0.98 & & \\
\hline $\mathbf{I}_{5}$ & 1.00 & 2.00 & 1.00 & 1.00 & 1.00 & 1.15 & 0.22 & 0.98 & & \\
\hline Sum & 4.33 & 5.20 & 12.0 & 4.50 & 4.50 & 5.25 & 1.00 & 5.34 & 0.09 & 0,08 \\
\hline \multicolumn{11}{|c|}{ Alternative $\mathbf{A}_{\mathbf{3}}$} \\
\hline & $\mathbf{I}_{\mathbf{1}}$ & $\mathbf{I}_{2}$ & $\mathbf{I}_{3}$ & $\mathbf{I}_{4}$ & $\mathbf{I}_{5}$ & GM & PV & $\mathbf{k}$ & CI & CR \\
\hline $\mathbf{I}_{1}$ & 1.00 & 1.00 & 3.00 & 3.00 & 1.00 & 1.55 & 0.29 & 1.07 & & \\
\hline $\mathbf{I}_{2}$ & 1.00 & 1.00 & 2.00 & 2.00 & 2.00 & 1.52 & 0.28 & 0.99 & & \\
\hline $\mathbf{I}_{3}$ & 0.33 & 0.50 & 1.00 & 1.00 & 1.00 & 0.70 & 0.13 & 1.05 & & \\
\hline $\mathbf{I}_{4}$ & 0.33 & 0.50 & 1.00 & 1.00 & 1.00 & 0.70 & 0.13 & 1.05 & & \\
\hline $\mathbf{I}_{5}$ & 1.00 & 0.50 & 1.00 & 1.00 & 1.00 & 0.87 & 0.16 & 0.98 & & \\
\hline Sum & 3.67 & 3.50 & 8.00 & 8.00 & 6.00 & 5.34 & 1.00 & 5.14 & 0.03 & 0.03 \\
\hline
\end{tabular}

GM-Geometric mean; PV-Priority vector; k-Eigenvalue; CI-Consistency index; $\mathbf{C R}$ - Consistency ratio; $\mathbf{A}_{\mathbf{1}}$-Development of a multi-functional centre; $\mathbf{A}_{\mathbf{2}}-$ Active conservation of the ruins; $\mathbf{A}_{\mathbf{3}}-$ Virtual museum; $\mathbf{I}_{\mathbf{1}}$ -Acceptable reconstruction costs for the buildings; $\mathbf{I}_{2}$-Nearness to infrastructure; $\mathbf{I}_{3}-$ Nearness to historic centres; $\mathbf{I}_{4}$-Nearness to natural sites; $\mathbf{I}_{5}$-Nearness to business centres; 1 Equal importance; 3 Moderate importance of one over another; 5 Essential or strong importance; 7 Very strong importance; 9 Extreme importance.

The nearness of the infrastructure $\left(\mathrm{I}_{2}\right)$ was more important than nearness to historic centres $\left(\mathrm{I}_{3}\right)$ and nearness of elements of the ecological network $\left(\mathrm{I}_{4}\right)$. This was because the goal was to ensure good connections with the surrounding area for social reasons, and so that services could be provided. The indicator had the same importance as nearness to businesses $\left(\mathrm{I}_{5}\right)$, which could benefit from the reconversion of the village. However nearness to historical centres $\left(\mathrm{I}_{3}\right)$ was somewhat more important than nearness to nature sites $\left(\mathrm{I}_{4}\right)$ - given the economic and social goals of the reconversion-and a little less important than the presence of businesses in the area $\left(\mathrm{I}_{5}\right)$. This is because it is presumed that the centre is above all of service to the rural area. Hence in the weightings vectors the highest values were allotted to $I_{2}$, nearness to infrastructure, followed by $\mathrm{I}_{3}$, nearness to historic centres. The lowest weighting was for nearness to elements of the ecological network.

For $\mathrm{A}_{2}$, the reconversion hypothesis, indicator $\mathrm{I}_{1}$, active conservation of the ruins was more important than nearness to historic centres $\left(\mathrm{I}_{3}\right)$, because these did not influence conserving natural resources, which was the objective of the action. However $I_{1}$ was as important as the other indicators. Nearness to infrastructure $\left(\mathrm{I}_{2}\right)$ was certainly clearly more important than nearness to historic centres $\left(\mathrm{I}_{3}\right)$ and farms $\left(\mathrm{I}_{4}\right)$. The roads are necessary for a planned use of the area, but may also include the creation of greenways. The weightings of the priority vector were reasonably homogeneous for indicators $\mathrm{I}_{1}, \mathrm{I}_{2}, \mathrm{I}_{4} \mathrm{e} \mathrm{I}_{5}$, while they it was perceptibly lower for $\mathrm{I}_{3}$, nearness to historic centres.

The village's main use is for tourism and culture for hypothesis $\mathrm{A}_{3}$, creation of an on site virtual museum. In this case possessing various infrastructure $\left(\mathrm{I}_{2}\right)$, the presence of rural buildings $\left(\mathrm{I}_{5}\right)$ and the economic advantages $\left(\mathrm{I}_{1}\right)$ are all of equal importance, as they guarantee that visitors have access to the area and to a network of rural support services, as well as the maintenance of the infrastructure of the area. By contrast profitability $\left(\mathrm{I}_{1}\right)$ is more important than nearness to historic centres $\left(I_{3}\right)$ or to nature areas $\left(\mathrm{I}_{4}\right)$, which have little influence on the character of the intervention. For these latter indicators it is clear that the presence of various structures $\left(\mathrm{I}_{2}\right)$ is most important. For the priority vectors the highest values were for $I_{1}$ and $I_{2}$, followed by $I_{5}$ and then by $I_{3}$ and $I_{4}$, which had equal values.

All the matrices were consistent. The values of the consistency index and the consistency ratio are shown in Table 2.

Transferring the values of the priority vectors into the general evaluation matrices (Table 3) allowed us to put the alternatives into an order of priority The sum of weightings method $\left(S_{i}\right)$ was used. In this method, for each single alternative, each attribute $\left(a_{n m}\right)$ given to the indicator is multiplied by the normalised weighting of the same indicator $\left(w_{i}\right)$ for the alternative under consideration. This is then summed with those of the same line, according to the following formula:

$$
S_{i}=\sum_{i} w_{i} \cdot a_{n m}
$$

Thus it became the ranking of the alternatives with respect to their weightings.

Alternative $A_{2}$ was the one which best satisfied the possible alternatives for reuse.

\subsubsection{Application Using Four Hierarchical Levels}

The pairwise comparison was carried out for the three 
Table 3. Prioritising the alternatives using three hierarchical levels.

\begin{tabular}{ccccccccccc}
\hline & \multicolumn{3}{c}{$\begin{array}{c}\text { Normalised } \\
\text { evaluation }\end{array}$} & \multicolumn{3}{c}{ PV } & \multicolumn{4}{c}{ priority } \\
\hline & $\mathbf{A}_{\mathbf{1}}$ & $\mathbf{A}_{\mathbf{2}}$ & $\mathbf{A}_{\mathbf{3}}$ & $\mathbf{A}_{\mathbf{1}}$ & $\mathbf{A}_{\mathbf{2}}$ & $\mathbf{A}_{\mathbf{3}}$ & $\mathbf{A}_{\mathbf{1}}$ & $\mathbf{A}_{\mathbf{2}}$ & $\mathbf{A}_{\mathbf{3}}$ \\
\hline $\mathbf{I}_{\mathbf{1}}$ & 0.00 & 1.00 & 0.75 & 0.32 & 0.24 & 0.29 & 0.00 & 0.24 & 0.22 \\
$\mathbf{I}_{\mathbf{2}}$ & 1.00 & 1.00 & 1.00 & 0.27 & 0.23 & 0.28 & 0.27 & 0.23 & 0.28 \\
$\mathbf{I}_{\mathbf{3}}$ & 0.25 & 0.75 & 0.75 & 0.19 & 0.10 & 0.13 & 0.05 & 0.07 & 0.10 \\
$\mathbf{I}_{\mathbf{4}}$ & 0.25 & 0.75 & 0.50 & 0.07 & 0.22 & 0.13 & 0.02 & 0.16 & 0.07 \\
$\mathbf{I}_{\mathbf{5}}$ & 0.25 & 0.75 & 0.75 & 0.15 & 0.22 & 0.16 & 0.04 & 0.16 & 0.12 \\
\hline & & & \multicolumn{4}{c}{ weighed sum } & $\mathbf{0 . 3 7}$ & $\mathbf{0 . 8 7}$ & $\mathbf{0 . 7 9}$
\end{tabular}

PV—Priority vector; $\mathbf{A}_{1}$-Development of a multi-functional centre; $\mathbf{A}_{2}-$ Active conservation of the ruins; $\mathbf{A}_{3}$-Virtual museum; $\mathbf{I}_{\mathbf{1}}$-Acceptable reconstruction costs for the buildings; $\mathbf{I}_{2}-$ Nearness to infrastructure; $\mathbf{I}_{3}-$ Nearness to historic centres; $\mathbf{I}_{4}$-Nearness to natural sites; $\mathbf{I}_{5}-$ Nearness to business centres.

hypotheses $A_{1}, A_{2}$ and $A_{3}$, for cost $(E)$, tourism and cultural uses $(\mathrm{T})$, social uses $(\mathrm{S})$ and development of an ecological network $(\mathrm{N})$.

In the pairwise comparison the Saaty Scale was used to give values to the responses to the following questions:

- For cost $(\mathrm{E})$, is the hypothesis in the column more economical, and if so by how much, than that in the line?

- For tourism and cultural uses (T), is the hypothesis in the column more important, and if so by how much, than that in the line?

- For social uses $(\mathrm{S})$, is the hypothesis in the column more important, and if so by how much, than that in the line?

- For development of an ecological network $(\mathrm{N})$ is the hypothesis in the column more important, and if so by how much, than that in the line?

The complete renovation of the buildings laid out in $A_{1}$ has a negative effect on the cost of the intervention when compared to the other two hypotheses, and in particularly in comparison with $\mathrm{A}_{2}$, in which only consolidation work would be carried out. Thus $\mathrm{A}_{2}$ was much more economical than $\mathrm{A}_{1}$ and considerably more economical than $\mathrm{A}_{3}$.

The comparisons with respect to the needs for tourism gave greater importance to hypotheses $A_{3}$ and $A_{2}$ than to $A_{1}$, while the latter was more important than $A_{3}$ and $A_{2}$ when reuse for social purposes was compared.

$\mathrm{A}_{2}$ was clearly better for creating an ecological network, especially when compared with multifunctional reconversion $\left(\mathrm{A}_{1}\right)$, but also when compared with creating an on site virtual museum $\left(\mathrm{A}_{3}\right)$.

Once again the matrices were consistent and weightings of the priority vectors were acceptable (Table 4).
Table 4. Pairwise comparison of the alternative reuses of the village.

\begin{tabular}{|c|c|c|c|c|c|c|c|c|}
\hline \multicolumn{9}{|c|}{ Economic advantages (E) } \\
\hline & $\mathbf{A}_{1}$ & $\mathbf{A}_{2}$ & $\mathbf{A}_{3}$ & GM & PV & $\mathbf{k}$ & CI & CR \\
\hline $\mathbf{A}_{1}$ & 1.00 & 0.11 & 0.20 & 0.28 & 0.06 & 0.87 & & \\
\hline $\mathbf{A}_{2}$ & 9.00 & 1.00 & 5.00 & 3.56 & 0.74 & 0.96 & & \\
\hline $\mathbf{A}_{3}$ & 5.00 & 0.20 & 1.00 & 1.00 & 0.21 & 1.28 & & \\
\hline Total & 15.00 & 1.31 & 6.20 & 4.84 & 1.00 & 3.12 & 0.06 & 0.10 \\
\hline \multicolumn{9}{|c|}{ Cultural and tourism uses $(\mathrm{T})$} \\
\hline & $\mathbf{A}_{1}$ & $\mathbf{A}_{2}$ & $\mathbf{A}_{3}$ & GM & $\mathbf{P V}$ & $\mathbf{k}$ & CI & $\mathbf{C R}$ \\
\hline $\mathbf{A}_{1}$ & 1.00 & 0.50 & 0.30 & 0.53 & 0.16 & 1.02 & & \\
\hline $\mathbf{A}_{2}$ & 2.00 & 1.00 & 1.00 & 1.26 & 0.38 & 0.96 & & \\
\hline $\mathbf{A}_{3}$ & 3.33 & 1.00 & 1.00 & 1.49 & 0.45 & 1.05 & & \\
\hline Total & 6.33 & 2.50 & 2.30 & 3.29 & 1.00 & 3.03 & 0.01 & 0.03 \\
\hline \multicolumn{9}{|c|}{ Social use (S) } \\
\hline & $\mathbf{A}_{1}$ & $\mathbf{A}_{2}$ & $\mathbf{A}_{3}$ & GM & PV & $\mathbf{k}$ & CI & CR \\
\hline $\mathbf{A}_{1}$ & 1.00 & 5.00 & 3.00 & 2.47 & 0.65 & 0.99 & & \\
\hline $\mathbf{A}_{2}$ & 0.20 & 1.00 & 0.50 & 0.46 & 0.12 & 0.98 & & \\
\hline $\mathbf{A}_{3}$ & 0.33 & 2.00 & 1.00 & 0.87 & 0.23 & 1.03 & & \\
\hline Total & 1.53 & 8.00 & 4.50 & 3.80 & 1.00 & 3.00 & 0.00 & 0.00 \\
\hline \multicolumn{9}{|c|}{ Developing an ecological network (N) } \\
\hline & $\mathbf{A}_{1}$ & $\mathbf{A}_{2}$ & $\mathbf{A}_{3}$ & GM & PV & $\mathbf{k}$ & CI & CR \\
\hline $\mathbf{A}_{1}$ & 1.00 & 0.20 & 0.50 & 0.46 & 0.12 & 0.98 & & \\
\hline $\mathbf{A}_{2}$ & 5.00 & 1.00 & 3.00 & 2.47 & 0.65 & 0.99 & & \\
\hline $\mathbf{A}_{3}$ & 2.00 & 0.33 & 1.00 & 0.87 & 0.23 & 1.03 & & \\
\hline Total & 8.00 & 1.53 & 4.50 & 3.80 & 1.00 & 3.00 & 0.00 & 0.00 \\
\hline
\end{tabular}

The weightings vectors in Table 4 show that the ecological network is cheaper and more suitable in hypothesis $A_{2}$, while $A_{3}$ is more suitable for tourism and $A_{1}$ for social uses.

Similar results were obtained when the weightings of the investigated indicators were compared for the three potential reuse hypotheses and the four requisites necessary for sustainable renovation and reuse (Table 5).

\subsubsection{Comparison of the Two Applications}

It becomes reasonably clear that hypothesis $A_{2}$ is better than the others is both procedures, with weightings of 0.87 and 1.89. The final results of the two approaches for the hierarchy of the other two hypotheses also agree, with $\mathrm{A}_{3}$ in second position (weightings 0.79 and 1.12) and $A_{1}$ last (weightings 0.37 and 0.99).

However the second application allowed us to distinguish preferences with respect to the identified requirements. Indeed if one looks at the results for each single 
Table 5. Prioritising the alternatives using four hierarchical levels.

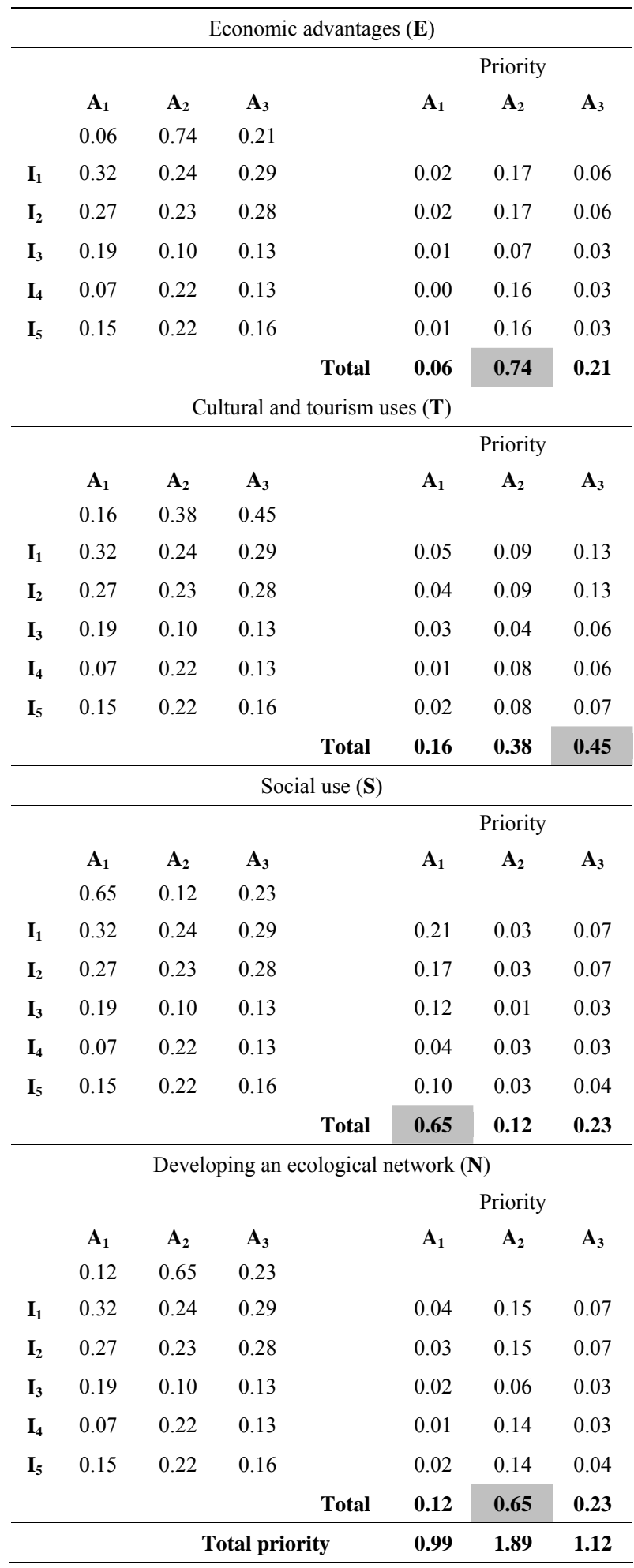

PV-Priority vector; $\mathbf{A}_{\mathbf{1}}$-Development of a multi-functional centre; $\mathbf{A}_{2}$ Active conservation of the ruins; $\mathbf{A}_{3}$-Virtual museum; $\mathbf{I}_{1}$-Acceptable reconstruction costs for the buildings; $\mathbf{I}_{2}-$ Nearness to infrastructure; $\mathbf{I}_{3}$ Nearness to historic centres; $\mathbf{I}_{\mathbf{4}}-$ Nearness to natural sites; $\mathbf{I}_{5}-$ Nearness to business centres. requisite, it becomes clear that hypothesis $\mathrm{A}_{2}$ is in first place for requisites $\mathrm{E}$ (weighing 0.74 ) and $\mathrm{N}$ (weighting 0.75 ), but the hierarchy is reversed for the other two hypotheses, because in hypothesis $A_{1}$ requisite $S$ is in first place (weighting 0.65), and in the last hypothesis, $\mathrm{A}_{3}$, requisite $\mathrm{T}$ is first (weighting 0.45 ).

\section{Conclusions}

The objective of the research was to discover or illustrate forms of sustainable restoration for historical rural buildings. This was done by using hierarchical analysis in a case study which was of historical and architectural relevance: the rural hamlet of Giuliano. Two hierarchies were created for a single objective and the results were compared.

Although the two procedures resulted in the same hypothesis for reuse being selected, the application based on four hierarchical levels provided additional data which could be used during the drafting of the project.

For example, in this specific case, although the possibility arose of drafting a project which was primarily aimed at preserving the ruins - which was the cheapest option and involved implementing an ecological network - it was also possible to consider minimal interventions which would meet the needs of tourism and social uses, while still maintaining the main goal of the chosen intervention [23]. Thus this means bringing into consideration the secondary results and not only the principal ones, given the fact that the weighting values for tourism and social uses were also high for solutions $\mathrm{A}_{1}$ and $\mathrm{A}_{3}$.

It is not difficult to respect these conditions. For example the master plan shown in Figure 6 is aimed at proposals of interventions designed to: consolidate the existing historical buildings in the village; improve the quality of urban and rural social life; redesign the public spaces by repairing the paving of the streets and square; planning new places of interest such as panoramic viewpoints and small widened spaces between the buildings, not excluding small structures for providing services to and assisting tourists. The public spaces might, on occasion, be used for shows or markets for local typical products. In this way, the social and cultural needs of the village would also be served: the ruins are the indispensable framework for promoting the culture, the landscape and local firms and farms.

Hierarchical analysis can be a useful support mechanism when re-qualifying buildings. It can give public authorities useful information on the possible choices that they have to make. Naturally it has to be followed up by careful planning and accurate realisation of the work. The results will only be positive if all the phases (from the choice of use to the actual work at the site) are approached with the aim of restoring a cultural resource to 


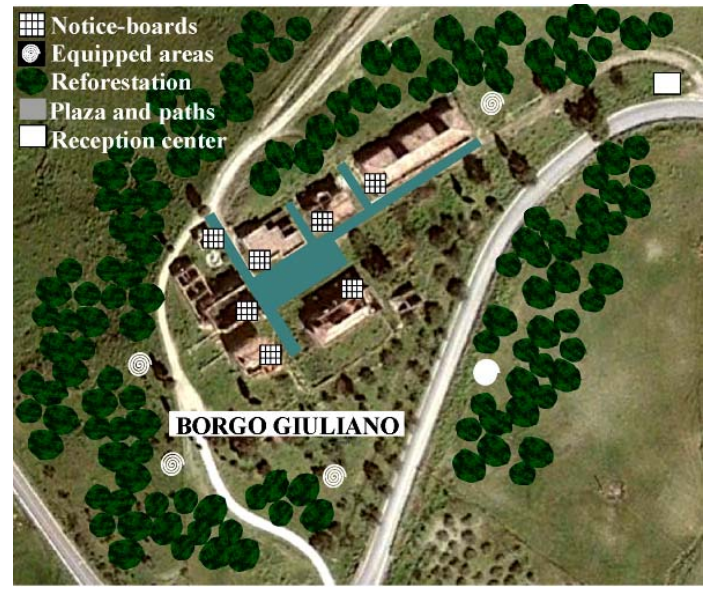

Figure 6. Master plan.

society, and making it also become an economic and social resource.

\section{REFERENCES}

[1] E. K. Zavadskas and J. Antucheviciene, "Multiple Criteria Evaluation of Rural Building's Regeneration Alternatives," Building and Environment, Vol. 42, No. 1, 2007, pp. 436-451. doi:10.1016/j.buildenv.2005.08.001

[2] D. Zupančič, "Dispersed Vernacular Structures as Landscape Development Potential: The Case of the Alpine Region in Slovenia," The Permanent European Conference for the Study of the Rural Landscape, 23rd Session -Landscapes, Identities and Development, Lisbon and Óbidos, 1-5 September 2008, pp. 1-9.

[3] A. Pennacchi, "Fascio e Martello," Laterza, Bari, 2008.

[4] P. Barbera, "Architettura in Sicilia tra le due Guerre," Sellerio Editore, Palermo, 2002.

[5] S. Di Fazio, "Libertinia: Un Borgo Rurale Fondato Negli Anni Venti in Sicilia," Tecnica Agricola, No. 1-2, 2005 , pp. 65-105.

[6] V. Sapienza, "La Colonizzazione del Latifondo Siciliano,” Edizioni Lussografia, Caltanissetta, 2010.

[7] S. Di Fazio, "Il Problema Insediativo e la Pianificazione del Territorio Rurale in Sicilia Nella Prima Metà del XX Secolo," Tecnica Agricola, Vol. 3-4, No. 1, 2002, pp. $1-26$.

[8] T. L. Saaty, "How to Make a Decision: The Analytic Hierarchy Process," European Journal of Operational Research, Vol. 48, No. 1, 1990, pp. 9-26. doi:10.1016/0377-2217(90)90057-I

[9] T. L. Saaty and M. Sagir, "Global Awareness, Future City Design and Decision Making," Journal of Systems Science and Systems Engineering, Vol. 21, No. 3, 2012, pp. 337-355. doi: $10.1007 / \mathrm{s} 11518-012-5196-\mathrm{Z}$
[10] T. L. Saaty, "Decision Making with the Analytic Hierarchy Process," International Journal of Services Sciences, Vol. 1, No. 1, 2008, pp. 83-98. doi:10.1504/IJSSCI.2008.017590

[11] William Ho, "Integrated Analytic Hierarchy Process and Its Applications-A Literature Review," European Journal of Operational Research, Vol. 186, No. 1, 2008, pp. 211-228. doi:10.1016/j.ejor.2007.01.004

[12] T. L. Saaty, "The Analytic Hierarchy Process," RWS Publications, Pittsburg, 1996.

[13] C. Y. Jim, "Old Stone Walls as an Ecological Habitat for Urban Trees in Hong Kong," Landscape and Urban Planning, Vol. 42, No. 1, 1998, pp. 29-43. doi:10.1016/S0169-2046(98)00072-3

[14] P. Russo, L. Carullo, L. Riguccio and G. Tomaselli, "Identification of Landscapes for Drafting Natura 2000 Network Management Plans: A Case Study in Sicily," Landscape and Urban Planning, Vol. 101, No. 3, 2011, pp. 228-243. doi:10.1016/j.landurbplan.2011.02.028

[15] Fegotto Virtual Museum, 2013. http://www.fegotto.it/

[16] P. Tassinari, D. Torreggiani, S. Benni, E. Dall'Ara and G. Pollicino, "The FarmBuiLD Model (Farm Building Landscape Design): First Definition of Parametric Tools," Journal of Cultural Heritage, Vol. 12, No. 4, 2011, pp. 485-493. doi:10.1016/j.culher.2011.05.001

[17] D. Torreggiani, P. Tassinari, "Landscape Quality of Farm Buildings: The Evolution of the Design Approach in Italy," Journal of Cultural Heritage, Vol. 13, No. 1, 2012, pp. 59-68. doi:10.1016/j.culher.2011.06.002

[18] D. Torreggiani, E. Dall'Ara and P. Tassinari, "The Urban Nature of Agriculture: Bidirectional Trends between City and Countryside," Cities, Vol. 29, No. 6, 2012, pp. 412416. doi:10.1016/j.cities.2011.12.006

[19] E. K. Zavadskas and J. Antucheviciene, "Multiple Criteria Evaluation of Rural Building's Regeneration Alternatives," Building and Environment, Vol. 42, No. 1, 2007, pp. 436-451. doi:10.1016/j.buildenv.2005.08.001

[20] P. Dal Sasso, G. S. Mugnozza, R. V. Loisi and G. Marinelli, "Proposte dì Recupero Delle Borgate Rurali in Puglia," Proceedings of the 9th National Conference AIIA, Thessaloniki, 12-16 September 2009, pp. 6-43.

[21] P. Dal Sasso and L. P. Caliandro, "The Role of Historical Agro-Industrial Buildings in the Study of Rural Territory," Landscape and Urban Planning, Vol. 96, No. 3, 2010, pp. 146-162. doi:10.1016/j.landurbplan.2010.03.003

[22] Landscape Plan of Sicily, 20s13. http://bca.regione.sicilia.it/ptpr/main/index.htm

[23] L. Jones-Walters, "Biodiversity in Multifunctional Landscapes," Journal for Nature Conservation, Vol. 16, No. 2, 2008, pp. 117-119. doi:10.1016/j.jnc.2008.03.001 